BMJ Open

Diabetes

Research

\& Care

\title{
Impact of a structured patient support program on adherence and persistence in basal insulin therapy for type 2 diabetes
}

\author{
Fang Liz Zhou, ${ }^{1}$ Jason Yeaw, ${ }^{2}$ Swapna U Karkare, ${ }^{2}$ Mitch DeKoven, ${ }^{2}$ \\ Paulos Berhanu, ${ }^{1}$ Timothy Reid ${ }^{3}$
}

To cite: Zhou FL, Yeaw J, Karkare SU, et al. Impact of a structured patient support program on adherence and persistence in basal insulin therapy for type 2 diabetes. BMJ Open Diab Res Care 2018;6:e000593. doi:10.1136/ bmjdrc-2018-000593

- Additional material is published online only. To view please visit the journal online (http://dx.doi.org/10.1136/ bmjdrc-2018-000593).

Received 2 August 2018 Revised 6 November 2018 Accepted 27 November 2018

Check for updates

\section{(c) Author(s) (or their} employer(s)) 2018. Re-use permitted under CC BY-NC. No commercial re-use. See rights and permissions. Published by BMJ.

${ }^{1}$ Sanofi US, Bridgewater, New Jersey, USA

${ }^{2}$ IQVIA, Fairfax, Virginia, USA

${ }^{3}$ Mercyhealth, Janesville,

Wisconsin, USA

Correspondence to

Dr Fang Liz Zhou;

Liz.Zhou@sanofi.com

\section{ABSTRACT}

Objective Treatment adherence and persistence are essential to achieving therapeutic goals in diabetes and may be improved by patient support programs (PSPs). The $\mathrm{COACH}$ Program was launched in 2015 with the goal of supporting patients with diabetes who are prescribed insulin glargine $300 \mathrm{U} / \mathrm{mL}$ (Gla-300). The study objective was to assess the program's impact on persistence and adherence with therapy among patients with type 2 diabetes.

Research design and methods A retrospective 12-month analysis was conducted to compare treatment adherence and persistence in patients treated with Gla300 who actively participated in the COACH PSP versus those who did not enroll using $\mathrm{COACH}$ engagement and claims data for the identification period from February 1 , 2016 to July 31,2016 . COACH $(n=544)$ and non-COACH $(n=544)$ participants were matched on selected baseline characteristics.

Results $\mathrm{COACH}$ participants were more likely to be adherent to $(68.0 \%$ vs $61.4 \%, p=0.0201 ; 0 R: 1.81$, $p=0.0002$ ) and persistent $(48.5 \%$ vs $42.1 \%, p=0.0309$; discontinuation HR: $0.60, p<0.0001$ ) with Gla-300 than non-COACH patients during the 12-month follow-up after controlling for clinical confounders. Additionally, both insulin-naive and basal insulin switcher $\mathrm{COACH}$ participants, respectively, were more likely to be adherent (OR: 2.25, $\mathrm{p}=0.0082$ and $\mathrm{OR}: 1.662, \mathrm{p}=0.0364$ ) and persistent (discontinuation HR: $0.53, p=0.0054$ and HR: $0.67, p=0.0492$ ) than non-COACH patients. Finally, $\mathrm{COACH}$ participants with greater level of engagement showed better persistence.

Conclusion These data demonstrate that participation and engagement with COACH PSPs are associated with improved persistence and adherence to Gla-300 among patients with type 2 diabetes.

\section{INTRODUCTION}

As with any disease, achievement of optimal therapeutic outcomes in type 2 diabetes relies on both adherence to and persistence with treatment. The treatment goal for glycemic control in most patients with type 2 diabetes is glycated hemoglobin A1C (A1C) $<7.0 \%$ (53 $\mathrm{mmol} / \mathrm{mol}) .{ }^{12}$ Despite advances in therapy, achievement of glycemic targets remains an

\section{Significance of this study}

What is already known about this subject?

- Improved treatment adherence and persistence are associated with greater hemoglobin A1C reductions and may therefore reduce diabetes-related complications.

- Patient support programs (PSPs) have shown to improve patient outcomes in real-world settings.

What are the new findings?

- Participation in the COACH PSP increased therapy adherence and persistence over a 12-month period.

- Therapy adherence and persistence increased in both insulin-naïve $\mathrm{COACH}$ participants and in $\mathrm{COACH}$ participants switching between basal insulins when compared with patients not enrolled in the $\mathrm{COACH}$ PSP.

How might these results change the focus of research or clinical practice?

- Robust evidence for improved persistence, adherence without increase in overall healthcare cost as an impact of PSP and consistency of the impact for different treatment groups may help inform clinical practice about the benefit of encouraging patients to leverage resources from PSP and in turn drive better outcome.

unmet need in a substantial proportion of patients with type 2 diabetes. ${ }^{3}{ }^{4}$ The inability to achieve or maintain glycemic control is associated with increased risk of diabetes-related complications. ${ }^{2}$ Improved treatment adherence and persistence are associated with greater A1C reductions and may therefore reduce diabetes complications. ${ }^{56}$ In addition, non-adherence to type 2 diabetes medications is associated with increased healthcare costs. ${ }^{7}$

Over the past decade or more, and according to the most recent national survey data, approximately $50 \%$ of people with diabetes in the USA do not achieve A1C $<7.0 \%(53 \mathrm{mmol} / \mathrm{mol}),{ }^{3}$ with poor medication adherence as the main driving factor 
for the treatment shortfall. ${ }^{8}$ Patient support programs (PSPs) can improve persistence with and/or adherence to medications for the treatment of chronic diseases. ${ }^{9-11}$ Furthermore, reports from the Healthcare Effectiveness Data and Information Set show that only about $40 \%$ and $30 \%$ of patients with diabetes in the commercially insured and Medicaid populations, respectively, achieve $\mathrm{A} 1 \mathrm{C}$ $<7.0 \%$ (53 mmol $/ \mathrm{mol}){ }^{8}$ The authors indicate that poor medication adherence is among the key drivers behind the discrepancy in rates of glycemic control attainments between randomized controlled trials (RCTs) and realworld settings, and highlight the need for improved patient support and provider support programs to enhance adherence.

Long-acting insulin analogs have demonstrated better persistence results when compared with human insulins, and better continuation rates when compared with other commonly prescribed injectable antidiabetes agents. ${ }^{12}$ Insulin glargine $300 \mathrm{U} / \mathrm{mL}$ (Gla-300) is a long-acting, second-generation, basal insulin analog that has been available in the USA since February 2015; it is indicated for improvement of glycemic control in adult patients with types 1 and 2 diabetes. ${ }^{13}$

Launched in 2015, the COACH Program ([COACH] Sanofi US, Bridgewater, New Jersey) is a PSP that is helping patients with diabetes, and who initiate Gla-300, to follow their treatment plan by delivering tailored disease education, product support, and encouragement for lifestyle changes, with the aim of ultimately improving glycemic control.

Patients received a welcome call from a nurse within a week after they enrolled into COACH PSP to introduce them to $\mathrm{COACH}$ and its online and offline components besides copay assistance for eligible patients. All enrollees had access to educational resources and interactive progress-tracking tools online, and received educational emails. In terms of offline offerings, participants also received tailored support via text messages and phone calls after completing the welcome call. This tailored support was provided based on patient-selected preferences. Nevertheless, those who actively participated in the program took the initiative to explore available resources, therefore may benefit from $\mathrm{COACH}$ more.

This study evaluated the real-world effectiveness of $\mathrm{COACH}$ on persistence with and/or adherence to Gla-300 treatment among patients with type 2 diabetes in the USA.

\section{RESEARCH DESIGN AND METHODS}

Study design

This was a retrospective, longitudinal cohort study conducted by deterministically linking data from the COACH Program to the IQVIA Integrated Data Warehouse ([IDW] IQVIA, Fairfax, Virginia) of administrative claims data. $=$

$\mathrm{COACH}$ data include patient identification and enrollment information, and information related to the extent of enrollee interaction with the program. Data from COACH were hosted and maintained by a designated third-party vendor. The IDW database contains data from multiple designated health channels in the USA, including hospitals, providers and pharmacies. When patients enrolled in $\mathrm{COACH}$, they provide consent of sharing protected health information and allow their data to be used for research. The sponsor had no access to the patient health information (PHI). For the purpose of this study, both pharmacy and medical claims data were used. A deterministic matching algorithm was used to link patients across the COACH and IDW databases by means of patient first name, last name, date of birth, gender, and zip code; this ensured continuity of patient records across data set types by using actual patient information. Confidential data were managed in a separate database by a third-party vendor according to standard compliance rules.

The patient identification period spanned from February 1, 2016 through July 31, 2016, with the COACH Program enrollment period between March 1, 2016 and June 30, 2016. The first prescription of Gla-300 within the identification period was considered the index date. Eligible patients had a 6-month baseline period prior to the index date and a 12-month follow-up period following the index date. Overall inclusion criteria were $\geq 1$ pharmacy claim for Gla-300; database activity for the duration of the 180 days immediately preceding the 6-month baseline period; pharmacy stability during baseline (defined as consistent reporting of data by the pharmacy associated with the index prescription; $\geq 80 \%$ coverage rate for each month in the 6 -month baseline period and the month of the index date); $\geq 1$ diagnosis code for type 2 diabetes (International Classification of Diseases [ICD], Ninth Revision codes 250.x0, 250.x2, or ICD-10 E11.xx); and age $\geq 18$ years on index date. The exclusion criteria were $\geq 1$ pharmacy claim for another basal insulin on or during the 14 days preceding the index date and data quality issues (ie, invalid year of birth, gender, or health plan enrollment dates) (online supplementary figure 2).

\section{Patient cohorts}

Patients with type 2 diabetes were stratified into cohorts based on participation in the $\mathrm{COACH}$ Program. $\mathrm{COACH}$ participants were patients enrolled in $\mathrm{COACH}$ between March 1, 2016 and June 30, 2016, and who had any of the following interactions with $\mathrm{COACH}$ within 2-3 months of enrollment: (1) completion of a welcome call; (2) participation in product training; (3) logging in to the online portal at least once after registration/enrollment; or (4) a response to $\geq 1$ text message after activation. Non-COACH patients were identified in the IDW database by their initial prescription for Gla-300 during the identification period, but did not enroll in COACH. To address putative selection bias, $\mathrm{COACH}$ participants were matched to non-COACH patients at a 1:1 ratio on five demographic and cost variables (eg, age group, gender, geographic region, health plan type, and preindex total 
healthcare cost category) and on insulin-naive versus basal insulin switcher status. Patients who could not be matched were excluded from the study. Patient cohorts were further categorized into two sets of subcohorts based on preindex medication exposure: patients were categorized as either insulin-naive if they had $\geq 2$ claims for oral antidiabetes drugs or a $\geq 1$ glucagon-like peptide- 1 receptor agonist claim, but no claims for insulin prior to Gla-300 initiation, or as basal insulin switchers if they had $\geq 1$ prescription claim for another basal insulin during the baseline period before switching to Gla-300.

$\mathrm{COACH}$ participants were further categorized into exploratory subcohorts based on their level of engagement after enrollment in COACH. Patients classified as engaged level 2 met $\geq 1$ of the following criteria: (1) completed a second call, or any of calls 3-6, about dose titration; (2) logged into the online portal $\geq 4$ times after registration; (3) responded to $\geq 3$ text messages after activation; or (4) enrolled in product training and completed any of the following: welcome call, $\geq 1$ online portal log in, or response to $\geq 1$ text message. Engaged level 1 patients were those who could not be classified as engaged level 2. Engagement levels 1 and 2 were matched separately.

\section{Outcomes}

Adherence with and persistence to Gla-300 were evaluated at 6 and 12 months postindex date. ${ }^{14}$ Adherence was defined as the proportion of days covered (total days supplied on the claim divided by the number of days in refill interval, assuming all medications are consumed as prescribed) using a cut-off of $\geq 80 \%$ to define adherent. ${ }^{14}{ }^{15}$ Persistence was defined as the percentage of patients remaining on Gla-300 therapy without discontinuation. Therapy was considered discontinued if the prescription was not refilled within the expected time of medication coverage, defined as the 90th percentile of the time between the index Gla-300 claim date and the refill date, stratified by the metric quantity supplied, observed during the follow-up period. ${ }^{5}$ The number of persistent days was the cumulative number of days a patient was prescribed Gla-300 without discontinuation. All-cause and diabetes-related healthcare resource utilization and direct costs were measured and reported at both 6 and 12 months postindex date.

\section{Statistical analyses}

Data were modeled a priori according to the statistical analysis plan. Matched cohorts were compared using McNemar's test for categorical variables and Wilcoxon signed-rank test for continuous variables for matched cohorts. To adjust for confounders, adherence to Gla-300 was also examined using logistic regression models. Cox proportional hazard model was used to assess the risk of Gla-300 discontinuation. Generalized estimating equation (GEE) models for matched cohorts were run to evaluate differences in total all-cause costs over the postindex period for $\mathrm{COACH}$ participants versus non-COACH patients; a GEE with a log-link function and gamma error-term distribution was used.

\section{RESULTS}

\section{Baseline patient characteristics}

There were $4252 \mathrm{COACH}$ participants identified from the COACH Program enrollees between March 1, 2016 and June 30, 2016. Separately a total of 258758 patients with a Gla-300 prescription filled between February 1, 2016 and July 31, 2016 were identified in the IDW database as non-COACH patients. After application of the full inclusion/exclusion criteria, the final $\mathrm{COACH}$ participant cohort contained 545 patients, while the non-COACH patient cohort contained 78524 patients. After direct match, both matched cohorts consist of 544 patients (figure 1).

Patients in the COACH and the non-COACH cohorts were generally well matched on baseline demographics and clinical characteristics (table 1). The only statistically significant difference observed between the $\mathrm{COACH}$ and non-COACH cohorts was a lower proportion of patients in the COACH participant cohort receiving dipeptidyl peptidase- 4 inhibitors in the baseline period (52\% vs $76 \%$ for $\mathrm{COACH}$ vs non-COACH, respectively, $\mathrm{p}=0.0233)$. The subcohorts of switcher $(\mathrm{n}=277 /$ cohort $)$ and naive ( $\mathrm{n}=190 /$ cohort) patients were formed from the matched cohort. On average, patients were 56.5 years of age, $51.7 \%$ were men, more than half (60.5) were from the South census region, and the majority $(89.5 \%)$ had a third-party payer.

\section{Descriptive result}

In the unadjusted descriptive data set, COACH participants were significantly more adherent to and/ or persistent with Gla-300 treatment compared with matched non-COACH patients overall (adherence $68.0 \%$ vs $61.4 \%$, respectively, $\mathrm{p}=0.0201$; and persistence $48.5 \%$ vs $42.1 \%$, respectively, $\mathrm{p}=0.0309$ ) (online supplementary figure 1A). A higher proportion of $\mathrm{COACH}$ participants in the naive subcohort were more adherent and persistent compared with non-COACH patients (adherence $67.4 \%$ vs $54.2 \%, \mathrm{p}=0.0049$; and persistence $44.2 \%$ vs $32.1 \%, \mathrm{p}=0.0183$ ). The duration of persistence over 12 months of follow-up was also significantly longer for $\mathrm{COACH}$ participants compared with non-COACH patients (mean/median [SD] 285.5/348 [90.9] days vs 242.0/304 [101.7] days, respectively, $\mathrm{p}<0.0001$ ) (online supplementary figure 1). In the naive subcohort, the duration of persistence was longer for $\mathrm{COACH}$ participants compared with non-COACH patients (mean [SD] 276.9 [92.3] days vs 240.4 [103.1] days, $\mathrm{p}=0.0004$ ). Additionally, a trend toward greater persistence was observed for engaged level 2 patients than engaged level 1 patients ( $54 \%$ vs $42 \%, \mathrm{p}=0.0508$ ) (online supplementary figure $1)$. Finally, the duration of persistence was significantly longer in $\mathrm{COACH}$ participants in the engagement level 2 group when compared with the engagement level 1 


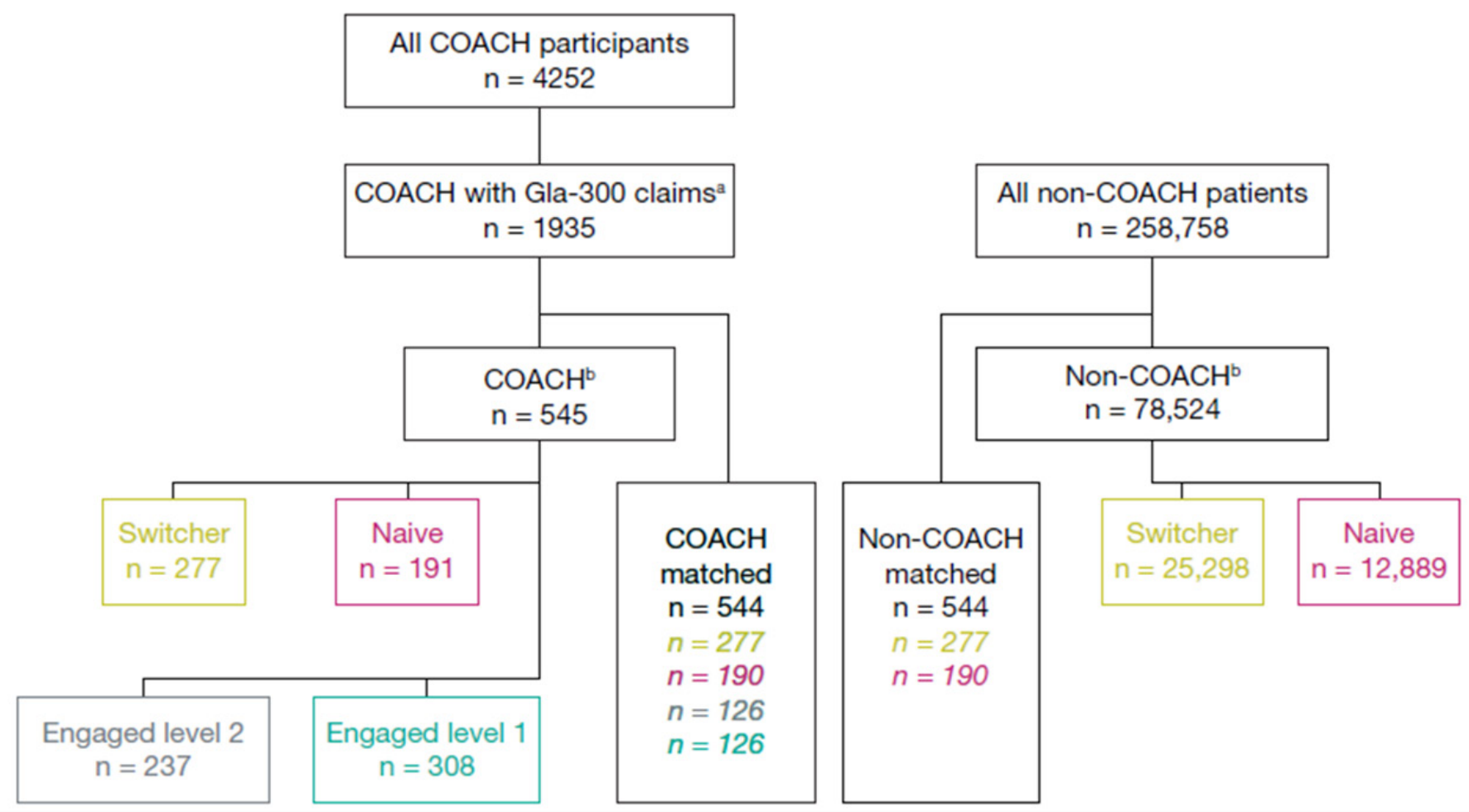

Figure 1 Attrition diagram. Gla-300, insulin glargine $300 \mathrm{U} / \mathrm{mL}$. ${ }^{a} \mathrm{Gla}-300$ claims in the identification period. ${ }^{\mathrm{b}}$ After applying inclusion/exclusion criteria listed in the text. Switcher: switching from another insulin; naïve: insulin-naïve; engagement level: amount of interaction with the COACH Program ('2' higher level of engagement than '1').

group (mean [SD] 300 [80.5] days vs 275 [95.8] days, $\mathrm{p}=0.0149$ ) (online supplementary figure 1 ). These treatment patterns were also observed at 6 months (online supplementary figure 2).

\section{Multivariate results}

In the multivariate adjusted analysis of the 12-month follow-up data, there was a 1.8 times greater likelihood of adherence to Gla-300 in the COACH participant cohort compared with the non-COACH patient cohort (OR 1.81, $\mathrm{p}=0.0002$ ) (online supplementary table 1 ; figure 2 ). Similarly, there was a $40 \%$ lower risk of Gla-300 discontinuation among patients in the COACH participant cohort compared with those in the non-COACH patient cohort (discontinuation HR 0.60, $\mathrm{p}=0.0001,95 \%$ CI 0.46 to 0.77 ) (table 2, figure 2B).

Naive and switcher subcohorts in the COACH participant cohort demonstrated better adherence when compared with non-COACH patients (OR 2.25, $\mathrm{p}=0.0082$ vs OR 1.66, $\mathrm{p}=0.0364$ ) (figure 2). Similarly, the risk of Gla-300 discontinuation was $47 \%$ lower for COACH participants than for non-COACH patients in the naive (HR $0.53, p=0.0054,95 \%$ CI 0.34 to 0.83 ) and switcher (HR $0.67, \mathrm{p}=0.0492,95 \%$ CI 0.45 to 0.99 ) subcohorts (figure 2B).

The level of engagement in $\mathrm{COACH}$ also affected persistence, but not adherence, at the 12-month follow-up. COACH participants with engagement level 2 also had a significantly decreased risk of Gla-300 discontinuation compared with those at engagement level 1
(HR 0.47, $\mathrm{p}=0.0095,95 \%$ CI 0.28 to 0.81 ) (figure 2). Patients at engagement level 2 had comparable odds of being adherent when compared with those at engagement level 1 (OR 1.67, $\mathrm{p}=0.1314$ ) (figure 2).

\section{Healthcare costs}

In the multivariate adjusted analysis, the total all-cause healthcare costs during the 12-month follow-up period were not significantly different for patients in the COACH participant cohort compared with those in the non-COACH patient cohort (12-month cost ratio 1.53, $\mathrm{p}=0.4449$ ).

\section{DISCUSSION}

PSPs aimed at improving medication adherence and/ or persistence play a key role in optimizing patient care and maximizing outcomes. Data indicate that real-world A1C goal attainment lags substantially behind that seen in RCTs. ${ }^{8}$ In this study, participation in the COACH PSP increased adherence to and/or persistence with Gla-300 treatment among patients with type 2 diabetes. These outcomes are achieved irrespective of whether patients initiate basal insulin therapy with Gla-300 or switch to Gla-300 from another basal insulin therapy.

Our study adds to an already substantial body of supportive evidence which contributes to the inclusion of patient education in current type 2 diabetes management approaches to encourage patient adherence. ${ }^{2}$ As a such, diabetes self-management education and support 
Table 1 Baseline demographic and clinical characteristics of the matched patient cohorts

COACH participants $(n=544)$ Non-COACH patients $(n=544) \quad P$ value

\begin{tabular}{|c|c|c|c|}
\hline Age, mean (SD), years & $56.5(9.80)$ & $56.5(10.5)$ & \\
\hline \multicolumn{4}{|l|}{ Age, group, years, n (\%) } \\
\hline $18-34$ & $14(2.57)$ & $14(2.57)$ & \\
\hline $35-44$ & $45(8.27)$ & $45(8.27)$ & \\
\hline $45-54$ & $149(27.39)$ & 149 (27.39) & \\
\hline $55-64$ & $241(44.30)$ & $241(44.30)$ & \\
\hline $65+$ & $95(17.46)$ & $95(17.46)$ & \\
\hline Male gender, n (\%) & $281(51.65)$ & $281(51.65)$ & \\
\hline \multicolumn{4}{|l|}{ Payer type, n (\%) } \\
\hline Cash & $14(2.57)$ & $14(2.57)$ & $\mathrm{NA}^{*}$ \\
\hline Medicaid & $1(0.18)$ & $1(0.18)$ & \\
\hline Medicare & $42(7.72)$ & $42(7.72)$ & \\
\hline Third party & 487 (89.52) & 487 (89.52) & \\
\hline \multicolumn{4}{|l|}{ Region n (\%) } \\
\hline Northeast & $36(6.62)$ & $36(6.62)$ & \\
\hline Midwest & $122(22.43)$ & $122(22.43)$ & \\
\hline South & $329(60.48)$ & $329(60.48)$ & \\
\hline West & $57(10.48)$ & $57(10.48)$ & \\
\hline \multicolumn{4}{|l|}{ Prescriber, n (\%) } \\
\hline Endocrinologist & $163(29.96)$ & $159(29.23)$ & 0.5678 \\
\hline PCP/FP/GP/IM & $362(66.54)$ & $373(68.57)$ & \\
\hline Other & $19(3.49)$ & $12(2.21)$ & \\
\hline CCl score, mean (SD) & $2.1(1.40)$ & $2.0(1.40)$ & 0.4155 \\
\hline \multicolumn{4}{|l|}{ Comorbidities, n (\%) } \\
\hline Anxiety & $23(4.23)$ & $35(6.43)$ & 0.0961 \\
\hline Coronary artery disease & $51(9.38)$ & $59(10.85)$ & 0.4042 \\
\hline Depression & $36(6.62)$ & $36(6.62)$ & 1.0000 \\
\hline Diabetic neuropathy & $79(14.52)$ & $90(16.54)$ & 0.3643 \\
\hline Dyslipidemia & 279 (51.29) & $266(48.90)$ & 0.4347 \\
\hline Hypertension & $348(63.97)$ & $328(60.29)$ & 0.2095 \\
\hline Renal impairment & $72(13.24)$ & $58(10.66)$ & 0.1936 \\
\hline Stroke/TIA & $19(3.49)$ & $24(4.41)$ & 0.4233 \\
\hline Hypoglycemia events, n (\%) & $11(2.02)$ & $16(2.94)$ & 0.3173 \\
\hline Total pharmacy costs, $\uparrow$ mean (SD), US\$ & $5525.20(5908.50)$ & $5580.40(6273.80)$ & 0.8202 \\
\hline Total medical costs, $\nmid$ mean (SD), US\$ & $4299.50(13900.20)$ & $4833.10(12564.40)$ & 0.4649 \\
\hline \multicolumn{4}{|l|}{ Diabetes regimen, $\mathrm{n}(\%)$} \\
\hline Patients using OADs & $412(75.74)$ & $425(78.13)$ & 0.2836 \\
\hline Biguanides & $282(51.84)$ & $292(53.68)$ & 0.5336 \\
\hline DPP-4 inhibitors & $52(9.56)$ & $76(13.97)$ & 0.0233 \\
\hline Fixed-dose combination OADs & 75 (13.79) & $72(13.24)$ & 0.7815 \\
\hline SGLT2 inhibitors & $109(20.04)$ & $104(19.12)$ & 0.6860 \\
\hline Sulfonylureas & $171(31.43)$ & $163(29.96)$ & 0.5913 \\
\hline TZDs & $33(6.07)$ & $31(5.70)$ & 0.7995 \\
\hline GLP-1 RAs & $119(21.88)$ & 104 (19.12) & 0.2595 \\
\hline RAls & 149 (27.39) & $172(31.62)$ & 0.0630 \\
\hline
\end{tabular}


Table 1 Continued

COACH participants $(n=544)$ Non-COACH patients $(n=544) \quad P$ value

Number of OADs, mean (SD)

$3.8(3.50)$

$3.9(3.80)$

0.8089

${ }^{*} \mathrm{P}$ values not applicable as these variables were used for direct matching.

†6-month costs.

CCI, Charlson Comorbidity Index; DPP-4, dipeptidyl peptidase-4; FP, family practitioner; GLP-1 RA, glucagon-like peptide-1 receptor agonist; GP, general practitioner; IM, internal medicine; NA, not applicable; OAD, oral antidiabetes drug; PCP, primary care provider; RAI, rapid-acting insulin; SGLT2, sodium glucose co-transporter 2; TIA, transient ischemic attack; TZD, thiazolidinedione.

(DSMES) programs continue to be a key element of diabetes care. ${ }^{16}$ The importance of adherence is underlined by its inclusion as a metric in the criteria used to help assess US health plan quality and performance in the Centers for Medicare and Medicaid Services star ratings. ${ }^{17}$
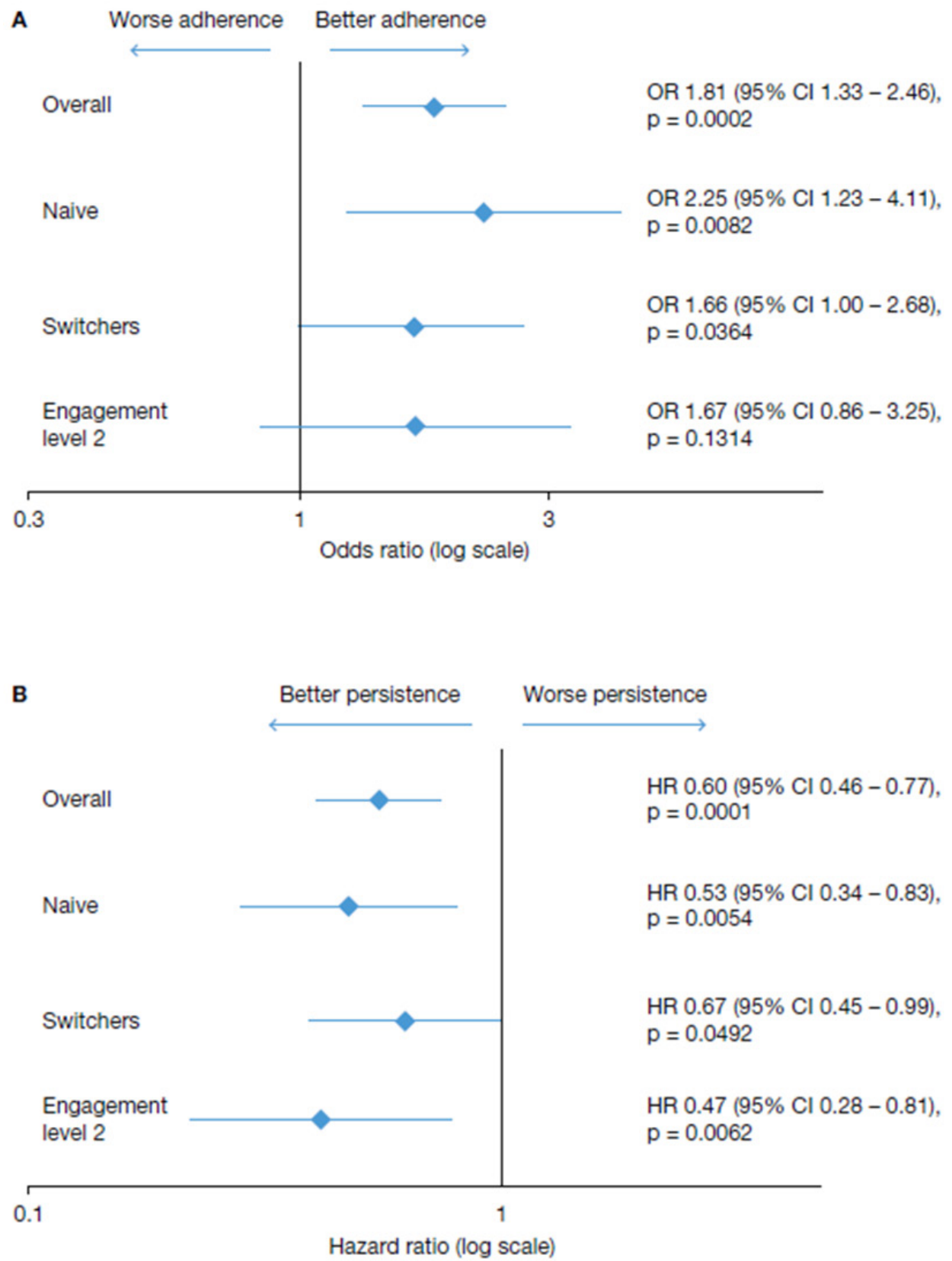

Figure 2 Multivariate analysis of (A) adherence (\% adherent) and (B) persistence (risk of discontinuation). 
Table 2 Cox proportional hazard model of discontinuation of Gla-300 among COACH participants compared with non$\mathrm{COACH}$ patients (overall sample)

\begin{tabular}{|c|c|c|c|c|c|}
\hline \multirow[b]{2}{*}{ Variable } & \multirow[b]{2}{*}{ Coefficient } & \multirow[b]{2}{*}{ HR } & \multicolumn{2}{|l|}{$95 \% \mathrm{Cl}$} & \multirow[b]{2}{*}{$P$ value } \\
\hline & & & Lower limit & Upper limit & \\
\hline $\mathrm{COACH}$ participation & -0.517 & 0.596 & 0.461 & 0.771 & $<0.0001$ \\
\hline $\mathrm{CCl}$ score & 0.157 & 1.169 & 1.000 & 1.368 & 0.0502 \\
\hline \multicolumn{6}{|l|}{ Physician specialization at index } \\
\hline Endocrinologist & 0.556 & 1.744 & 0.621 & 4.899 & 0.2912 \\
\hline $\mathrm{PCP} / \mathrm{FP} / \mathrm{GP} / \mathrm{IM}$ & 0.269 & 1.309 & 0.486 & 3.525 & 0.5944 \\
\hline Preindex hospitalization & 0.614 & 1.847 & 1.055 & 3.234 & 0.0316 \\
\hline Rebate marker & 0.471 & 1.601 & 0.928 & 2.762 & 0.0907 \\
\hline Preindex hypoglycemia event & 0.118 & 1.126 & 0.425 & 2.981 & 0.8115 \\
\hline \multicolumn{6}{|l|}{ Preindex antidiabetes drug use } \\
\hline Biguanides & -0.147 & 0.863 & 0.613 & 1.215 & 0.3991 \\
\hline DPP-4 inhibitors & -0.081 & 0.922 & 0.556 & 1.530 & 0.7532 \\
\hline $\begin{array}{l}\text { Fixed-dose combination } \\
\text { OADs }\end{array}$ & -0.267 & 0.766 & 0.461 & 1.272 & 0.3026 \\
\hline SGLT2 inhibitors & 0.131 & 1.140 & 0.742 & 1.75 & 0.5505 \\
\hline Sulfonylureas & -0.156 & 0.856 & 0.602 & 1.216 & 0.3843 \\
\hline TZDs & -0.254 & 0.776 & 0.413 & 1.457 & 0.4299 \\
\hline GLP-1 RAs & -0.653 & 0.520 & 0.343 & 0.790 & 0.0022 \\
\hline RAls & 0.029 & 1.030 & 0.662 & 1.602 & 0.8971 \\
\hline \multicolumn{6}{|l|}{ Preindex comorbidities } \\
\hline Anxiety & -0.783 & 0.457 & 0.208 & 1.001 & 0.0504 \\
\hline Coronary artery disease & 0.308 & 1.361 & 0.765 & 2.422 & 0.2949 \\
\hline Depression & 0.195 & 1.215 & 0.648 & 2.279 & 0.5435 \\
\hline Diabetic neuropathy & -0.339 & 0.712 & 0.456 & 1.112 & 0.1354 \\
\hline Dyslipidemia & 0.274 & 1.315 & 0.942 & 1.835 & 0.1076 \\
\hline Hypertension & 0.020 & 1.020 & 0.722 & 1.443 & 0.9090 \\
\hline Renal impairment & -0.095 & 0.909 & 0.513 & 1.613 & 0.7453 \\
\hline Stroke/TIA & 0.736 & 2.087 & 0.757 & 5.755 & 0.1549 \\
\hline
\end{tabular}

CCI, Charlson Comorbidity Index; DPP-4, dipeptidyl peptidase-4; FP, family practitioner; GLP-1 RA, glucagon-like peptide-1 receptor agonist; Gla-300, insulin glargine $300 \mathrm{U} / \mathrm{mL}$; GP, general practitioner; IM, internal medicine; OAD, oral antidiabetes drug; PCP, primary care provider; RAI, rapid-acting insulin; SGLT2, sodium glucose co-transporter 2; TIA, transient ischemic attack; TZD, thiazolidinedione.

Overall, in our study, $48.5 \%$ of COACH participants were persistent with Gla-300 during the 12-month follow-up period as compared with $42.1 \%$ of non-COACH participants. Differences in the definitions of persistence used between studies complicate comparisons with data within the peer-reviewed literature. Data from studies examining 12-month basal insulin treatment persistence in insulin-naive patients in the USA range from $26.5 \%$ to $80.1 \% .^{18-20}$ Notably, patients enrolled in commercial health plans, who make up the majority of patients in the COACH Program, appear to show lower levels of persistence. $^{19}$

Our analysis supports evidence in the literature suggesting that PSPs improve outcomes in a variety of chronic diseases, including diabetes. ${ }^{21}$ The evidence suggests that PSPs have a positive impact on a range of critical measures including adherence and persistence, ${ }^{911}$ clinical and healthcare utilization, patient quality of life ${ }^{9}$ and cost outcomes. ${ }^{10} 11$ In addition, participation in DSMES programs has been shown to reduce A1C levels, ${ }^{22}$ improve treatment adherence, and lead to lower healthcare resource utilization and costs. ${ }^{23}$

A number of studies have shown the benefits of methodologically diverse supportive patient education interventions in diabetes care. In the Mobile Diabetes Intervention Study, increased engagement in a web-based PSP improved glycemic outcomes ${ }^{24}$; similarly, patients with type 2 diabetes who participated in two pharmacist-driven programs achieved better glycemic outcomes than those not receiving the intervention. ${ }^{25}{ }^{26}$ In a pilot DSMES program, participants experienced reduced healthcare resource use and costs. ${ }^{27}$ Adherence and 
self-care improved significantly with a telephone-based intervention to improve care and clinical outcomes in type 2 diabetes. ${ }^{28}$ Additionally, a diabetes management education program based in South Texas is expected to result in substantial clinical benefits and healthcare cost savings. ${ }^{29}$ Finally, a structured multicomponent educational intervention program led to improved A1C, body weight, and cardiovascular outcomes. ${ }^{30}$

The PSPs discussed above are heterogeneous and include both one-to-one and group-based educational engagements, regular refill reminders, online educational interventions, and mailed communications. It is known that patient education and regular reminders can improve treatment adherence and quality of care; however, individualized approaches to PSPs are lacking. The COACH Program incorporated the above features and additionally offers targeted diabetes management through the use of proactive emails and text messages, which enables greater patient scalability and can be adjusted to meet individualized patient needs. Additionally, the COACH Program can support and complement the efforts of healthcare professionals as they provide comprehensive diabetes care for an ever increasing number of patients with the disorder.

\section{Limitations}

Our study is subject to a number of limitations; individuals who chose to enroll and actively participate in the PSP may be different from non-enrollees in terms of characteristics that were not observable in the data but could be related to the outcomes assessed. The use of claims data to estimate both adherence and persistence as evidence of prescription filling does not constitute evidence that a medicine was taken correctly, or if it was taken at all. Data from claims databases are subject to inaccuracies introduced through coding errors and other input errors made at study sites. Despite the use of direct matching and regression analysis to control for differences in baseline factors between cohorts, this observational retrospective database study cannot infer causality, and due to the continued presence of differences between groups, potential residual confounding may still exist. The database does not contain information on key clinical variables (including body weight and A1C levels) or on disease severity; these variables could not be controlled in the regression models. The analyses focused on patients who met pharmacy stability criteria, which may have resulted in the elimination of patients with different treatment patterns coincident with observation patterns. Although the study sample was drawn from a large data set, it may not be generalizable to other populations.

\section{CONCLUSIONS}

Participation in the COACH PSP was associated with a lower risk of Gla-300 discontinuation and improved adherence among patients with type 2 diabetes—benefits that may result in improved glycemic control. Similar results were observed among patients who were naive to basal insulin treatment and in those who switched from another basal insulin. Among $\mathrm{COACH}$ participants, a higher level of engagement was associated with a lower risk of Gla-300 discontinuation. Given that a lack of treatment adherence is a major risk factor for patients with type 2 diabetes not reaching their glycemic control goals in the real-world setting, PSPs like COACH may contribute to addressing unmet needs in this area.

Acknowledgements The authors received writing/editorial support in the preparation of this manuscript provided by Joseph Worrall, PhD, and Grace Richmond, PhD, of Excerpta Medica.

Contributorship FLZ, JY and TR designed the study. JY, SUK and MDK acquired the data. All authors analyzed and interpreted the data and made critical revisions to the manuscript.

Funding This work was supported by Sanofi.

Competing interests FLZ is an employee and stock/shareholder of Sanofi. JY, SUK, and MDK are employees of IQVIA, under contract with Sanofi and received funding from Sanofi for the conduct of this study. PB is an employee and stock/ shareholder of Sanofi. TR is a member of the speakers' bureau and/or consultant for Eli Lilly and Company, Janssen Pharmaceuticals, Novo Nordisk, and Sanofi US.

Patient consent for publication Not required.

Ethics approval Analysis was performed using de-identified data; therefore, no institutional review board review was required.

Provenance and peer review Not commissioned; externally peer reviewed.

Data sharing statement № additional data are available.

Open access This is an open access article distributed in accordance with the Creative Commons Attribution Non Commercial (CC BY-NC 4.0) license, which permits others to distribute, remix, adapt, build upon this work non-commercially, and license their derivative works on different terms, provided the original work is properly cited, appropriate credit is given, any changes made indicated, and the use is non-commercial. See: http://creativecommons.org/licenses/by-nc/4.0

\section{REFERENCES}

1. American Diabetes Association. Standards of medical care in diabetes. Diabetes Care 2017;40:S48-56.

2. Inzucchi SE, Bergenstal RM, Buse JB, et al. Management of hyperglycaemia in type 2 diabetes, 2015: a patient-centred approach. Update to a position statement of the American diabetes association and the European association for the study of diabetes. Diabetologia 2015;58:429-42.

3. Stark Casagrande S, Fradkin JE, Saydah SH, et al. The prevalence of meeting $\mathrm{A} 1 \mathrm{C}$, blood pressure, and LDL goals among people with diabetes, 1988-2010. Diabetes Care 2013;36:2271-9.

4. Khunti K, Ceriello A, Cos X, et al. Achievement of guideline targets for blood pressure, lipid, and glycaemic control in type 2 diabetes: a meta-analysis. Diabetes Res Clin Pract 2018;137:137-48.

5. Wei W, Pan C, Xie L, et al. Real-world insulin treatment persistence among patients with type 2 diabetes. Endocr Pract 2014;20:52-61.

6. Aikens JE, Piette JD. Longitudinal association between medication adherence and glycaemic control in type 2 diabetes. Diabet Med 2013;30:338-44.

7. Kennedy-Martin T, Boye KS, Peng X. Cost of medication adherence and persistence in type 2 diabetes mellitus: a literature review. Patient Prefer Adherence 2017;11:1103-17.

8. Edelman SV, Polonsky WH. Type 2 diabetes in the real world: the elusive nature of glycemic control. Diabetes Care 2017;40:1425-32.

9. Burudpakdee C, Khan ZM, Nanavaty M, et al. Impact of patient programs on adherence and persistence in inflammatory and immunologic diseases: a meta-analysis. Patient Preference and Adherence 2015;9:435-8.

10. Ganguli A, Clewell J, Shillington AC. The impact of patient support programs on adherence, clinical, humanistic, and economic patient outcomes: a targeted systematic review. Patient Prefer Adherence 2016;10:711-25.

11. Rubin DT, Mittal M, Davis M, et al. Impact of a patient support program on patient adherence to adalimumab and direct medical 
costs in Crohn's disease, ulcerative colitis, rheumatoid arthritis, psoriasis, psoriatic arthritis, and ankylosing spondylitis. J Manag Care Spec Pharm 2017;23:859-67.

12. McGovern A, Tippu Z, Hinton W, et al. Comparison of medication adherence and persistence in type 2 diabetes: a systematic review and meta-analysis. Diabetes, Obesity and Metabolism 2018;20:1040-3.

13. Toujeo, 2018. Prescribing Information. Available from: http:// products.sanofi.us/toujeo/toujeo.pdf [Accessed 2 Jul 2018].

14. Cramer JA, Roy A, Burrell A, et al. Medication compliance and persistence: terminology and definitions. Value Health 2008;11:44-7.

15. Choudhry NK, Shrank WH, Levin RL, et al. Measuring concurrent adherence to multiple related medications. Am J Manag Care 2009;15:457-64.

16. Beck J, Greenwood DA, Blanton L, et al. 2017 National standards for diabetes self-management education and support. Diabetes Educ 2018;44:35-50.

17. Centers for Medicare and Medicaid Services,Center for Medicare, 2018. Medicare 2017 part C \& D star rating technical Notes. First plan preview. Draft. Available from: https://www.cms.gov/Medicare/ Prescription-Drug-Coverage/PrescriptionDrugCovGenIn/Downloads/ 2017_Technical_Notes_preview_1_2016_08_03.pdf [Accessed 2 Jul 2018].

18. Davis KL, Tangirala M, Meyers JL, et al. Real-world comparative outcomes of US type 2 diabetes patients initiating analog basal insulin therapy. Curr Med Res Opin 2013;29:1083-91.

19. Wei W, Jiang J, Lou Y, et al. Benchmarking insulin treatment persistence among patients with type 2 diabetes across different U.S. Payer segments. J Manag Care Spec Pharm 2017;23:278-90.

20. Bonafede MM, Kalsekar A, Pawaskar M, et al. A retrospective database analysis of insulin use patterns in insulin-naïve patients with type 2 diabetes initiating basal insulin or mixtures. Patient Prefer Adherence 2010;4:147-6.
21. Rush KL, Hatt L, Janke R, et al. The efficacy of telehealth delivered educational approaches for patients with chronic diseases: a systematic review. Patient Educ Couns 2018;101:1310-21.

22. Klein HA, Jackson SM, Street K, et al. Diabetes self-management education: miles to go. Nurs Res Pract 2013;2013:1-15.

23. Duncan I, Ahmed T, Li QE, et al. Assessing the value of the diabetes educator. Diabetes Educ 2011;37:638-57.

24. Quinn CC, Butler EC, Swasey KK, et al. Mobile diabetes intervention study of patient engagement and impact on blood glucose: mixed methods analysis. JMIR Mhealth Uhealth 2018;6:e31.

25. Benedict AW, Spence MM, Sie JL, et al. Evaluation of a pharmacistmanaged diabetes program in a primary care setting within an integrated health care system. J Manag Care Spec Pharm 2018;24:114-22.

26. van Eikenhorst L, Taxis $K$, van Dijk L, et al. Pharmacist-led selfmanagement interventions to improve diabetes outcomes. A systematic literature review and meta-analysis. Front Pharmacol 2017;8:891.

27. Silveira LJ, Fleck SB, Sonnenfeld N, et al. Estimated cost savings: Everyone with Diabetes Counts (EDC) program. Fam Community Health 2018;41:185-119.

28. Sarayani A, Mashayekhi M, Nosrati M, et al. Efficacy of a telephonebased intervention among patients with type-2 diabetes; a randomized controlled trial in pharmacy practice. Int $J$ Clin Pharm 2018;40:345-53.

29. Kash BA, Lin SH, Baek J, et al. The diabetes management education program in South Texas: an economic and clinical impact analysis. Front Public Health 2017;5:345.

30. do Rosário Pinto M, Parreira P, Basto ML, et al. Impact of a structured multicomponent educational intervention program on metabolic control of patients with type 2 diabetes. BMC Endocr Disord 2017;17:77. 